\title{
A Preliminary Bloom's Taxonomy Assessment Of End-Of-Chapter Problems In Business School Textbooks
}

Jennings B. Marshall, Samford University, USA

Charles M. Carson, Samford University, USA

\begin{abstract}
This article examines textbook problems used in a sampling of some of the most common core courses found in schools of business to ascertain what level of learning, as defined by Bloom's Taxonomy, is required to provide a correct answer. A set of working definitions based on Bloom's Taxonomy (Bloom \& Krathwohl, 1956) was developed for the six different levels of the taxonomy. Because the course credit model relies so heavily on textbooks, the end of chapter problems for a leading text book in eight traditional business disciplines were evaluated. The initial findings indicate that the vast majority of end of chapter problems examined only required students to function at Level 1 (Knowledge) or Level 2 (Comprehension). While preliminary in nature, these data suggest the need for the use of other methods to challenge the student to think on higher cognitive levels.
\end{abstract}

Keywords: Bloom's Taxonomy, Assessment, End of Chapter Questions, Text Books

\section{INTRODUCTION}

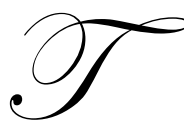

his paper explores the breadth of knowledge required to answer problems and cases contained in a set of textbooks commonly used in the core for a business school curriculum. This initial examination focuses only on one textbook per discipline. A working definition, based on Bloom's Taxonomy (Bloom \& Krathwohl, 1956), was developed by the authors of this paper in order to assess the level of knowledge required to work the problems presented in the end of chapter material. The initial data illustrate that chapter problems have become so narrowly focused as to present an unrealistic and naïve picture of what is required in order to address problems and issues commonly found in the business world.

In the authors' combined forty-one years of higher education teaching experience, we have observed a significant development in the utility of end of chapter problems in text books. Specifically, the level of difficulty and rigor in these problems would appear, to our eyes, to be on the decline. In identifying this problem we sought a means of more fully understanding the reasons for this decline. As an initial step, in what should be a long process, this paper seeks to examine the end of chapter problems commonly used in eight business school disciplines from a Bloom's Taxonomy (Bloom \& Krathwhol, 1956) perspective.

In recent years, shortcomings in higher education curriculum, in general and more specifically within schools of business, have been pointed out in surveys of employers as well as surveys of recent graduates. Deficiencies in basic skills, including the ability to make effective written and oral presentations, solve problems or to employ logical reasoning, have been identified. Growing evidence from such studies clearly suggest that the answer is not more and more three credit courses on highly specialized topics, but to assess the manner in which curricula are delivered to students in higher education. These failures show the need to shift to a new curriculum paradigm. The assessment movement has led to the paradigm shift in discussions of higher education quality. These discussions focus on how to expand learning outcomes, knowledge skills, and professional values and attitudes. 
The focus on outcomes has expanded a definition of learning from the limited set of knowledge imparted in the course to a curriculum based model. In the area of accounting, for example, expectations have been broadened to include indications of professional competencies and skills of lifetime learning (Deppe, Sonderegger, Stice, Clark, $\&$ Streuling, 1991). A number of programs in accounting are now emphasizing complex problem solving, critical thinking, communication of information and teamwork. Some form of assessment is now mandated over 40 states and over $90 \%$ of higher education institutions now claim to have assessment programs (El-Khawas, 1990). The current Association for the Advancement of Colleges and Schools of Business (AACSB) accreditation standards state that each degree program should be systematically monitored to assess its effectiveness (Eligibility Procedures and Accreditation Standards for Business Accreditation - www.aacsb.edu).

AACSB is now evaluating the role of the instructor, the development of courses, teaching effectiveness, and institutional innovation (Eligibility Procedures and Accreditation Standards for Business Accreditation www.aacsb.edu ). Increased attention is being placed on the ways in which a major within a business curriculum works as a total program, rather than as a set of discreet courses.

Key to the success of linking loosely defined courses within a curriculum would likely be a methodology that would tie together the knowledge attained in courses in a meaningful way for the students to comprehend and utilize said knowledge. For Total Quality Management (TQM) initiatives in higher education to become relevant, meaningful mechanisms must be utilized to create the linkages desired from the quality assessment movement. Business faculty want students to make connections between disciplines such as economics, accounting, finance, statistics, and marketing, but may find themselves to be inadequate to cover these areas because they feel that: one, they are outside of their disciplines and two, to spend time on those areas would take away from the time they need to impart the knowledge within their specific discipline during their limited three credit hour course. This connection between their course and the other disciplines can be achieved through the utilization of skillfully crafted problems utilizing a problem-based approach. When assessing the desired outcomes for students, all relevant stakeholders would likely concur that it is important that their higher education experiences take the student beyond knowledge and comprehension of a particular subject.

\section{METHODOLOGY FOR EVALUATION OF TEXTBOOKS}

Reliance on textbooks designed for a very specific subject matter, makes it very difficult to take students beyond the first two levels of Bloom's Taxonomy (Bloom \& Krathwohl, 1956). This is because many textbooks are written with a narrow focus and tend to impart only knowledge and comprehension within a very limited context. A working definition for scaling problems in the back of textbooks based on Bloom's Taxonomy (Bloom \& Krathwohl, 1956) was utilized to evaluate chapter problems and exercises found in business text books. The scale is given below:

\section{Bloom's Taxonomy Scale}

(Knowlege) The problem is at Level 1 - if it can be answered by simply recalling the information in that chapter; such as describing relationships, or defining terms.

(Comprehension) The problem is at Level 2 - if the question can be answered by restating or reorganizing material in a literal manner from the chapter.

(Application) The problem is at Level 3 - if the problem involves a new situation with minimal identification or prompting of the appropriate rule principle or concept.

(Analysis) The problem is at Level 4 - if to solve the problem the student must break an idea into its component parts for logical analysis. The problem requires the generalization to a new situation.

(Synthesis) The problem is at Level 5 - if the problem requires original creative thinking and the development of new tools to create a plan, or develop a model. 
(Evaluation) The problem is at Level 6 - if the problem requires the ability to judge and appreciate the value of ideas, procedures, and methods using appropriate criteria. The problem requires the student to compare and contrast the relative merits of ideas or concepts.

The authors, with the aid of colleagues in relevant disciplines, have reviewed leading textbooks from the most common fields of study contained within a business school curriculum. The fields and text books selected for review are summarized below in Table 1 .

Table 1

\begin{tabular}{|l|l|}
\hline \multicolumn{1}{|c|}{ Field } & \multicolumn{1}{c|}{ Text Selected } \\
\hline Economics & McConnell-Brue: (2005) Economics - Principles, Problems and Policies, 16th Edition. \\
\hline Statistics & $\begin{array}{l}\text { Anderson, David R., Sweeney, Dennis J., and Williams, Thomas A., (2005) Statistics For Business and } \\
\text { Economics, }{ }^{\text {th }} \text { Edition. }\end{array}$ \\
\hline Org Behavior & Robbins, Stephen P., (2005) Organizational behavior, 11 ${ }^{\text {th }}$ Edition. \\
\hline Marketing & Boone, Louis E., and Kurtz, David L., (2006) Contemporary Marketing, 12 ${ }^{\text {th }}$ Edition. \\
\hline Finance & $\begin{array}{l}\text { Ross, Stephen A., Westerfield, Randolph W., and Jordan, Bradforf D., (2004) Essentials of Corporate } \\
\text { Finance, } 4^{\text {th }} \text { Edition }\end{array}$ \\
\hline Accounting & $\begin{array}{l}\text { Kimmel, Paul D., Weygandt, Jerry J., and Kieso, Donald E., (2003) Financial Accounting: } \text { tools for } \\
\text { business decision making, 3 }{ }^{\text {rd }} \text { Edition. }\end{array}$ \\
\hline InfoTech & Laudon, Kenneth C. and Laudon, Jane P. (2004) Management Information Systems, ${ }^{\text {th }}$ Edition. \\
\hline Operations & Schonberger, Richard J. and Knod, Edward M., (2001) Operations Management, $5^{\text {th }}$ Edition. \\
\hline
\end{tabular}

\section{FINDINGS}

Our review of these texts uncovered some areas of similarity. Chapters from these textbooks tended to have a common format. Learning objectives for the chapters were usually defined in the introduction. The chapters typically contained content that was linked to business practices. Bullet points were in the margins or at the end of each chapter that reviewed the key points contained within the chapter. The exercises and/or end of chapter problems or cases generally followed a review of those key points. Textbooks reviewed for this paper averaged 28.5 problems per chapter.

The evaluation of the end of chapter problems using Bloom's Taxonomy (Bloom \& Krathwohl, 1956) is given below. The results have been reviewed and categorized in a summary Table 2 .

Table 2

Evaluation of Textbooks Based on Bloom's Taxonomy

\begin{tabular}{|c|c|c|c|c|c|c|c|}
\hline Discipline & LEVEL 1 & LEVEL 2 & LEVEL 3 & LEVEL 4 & LEVEL 5 & LEVEL 7 & total \\
\hline & Knowledge & Comprehension & Application & Analysis & Synthesis & Evaluation & \\
\hline Economics & 16 & 65 & 4 & 0 & 0 & 0 & 85 \\
\hline Statistics & 200 & 61 & 3 & 0 & 0 & 0 & 264 \\
\hline Org Behavior & 22 & 13 & 7 & 3 & 2 & 0 & 47 \\
\hline Marketing & 85 & 11 & 12 & 0 & 0 & 0 & 108 \\
\hline Finance & 36 & 179 & 3 & 0 & 0 & 0 & 218 \\
\hline Accounting & 20 & 32 & 9 & 0 & 0 & 0 & 61 \\
\hline InfoTech & 0 & 54 & 32 & 1 & 0 & 0 & 87 \\
\hline Operations & 0 & 48 & 24 & 0 & 0 & 0 & 72 \\
\hline & & & & & & & \\
\hline & 379 & 463 & 94 & 4 & 2 & 0 & 942 \\
\hline
\end{tabular}


Forty percent of the problems were at the most basic level of Knowledge, followed by Comprehension with 49 percent. This indicates that almost 90 percent of all the problems were at these two most basic levels based on the Taxonomy. Only ten percent of the problems reviewed from the textbooks that have been identified as leading textbooks in these fields, challenge students at the Application level or higher on Bloom's Taxonomy (Bloom \& Krathwohl, 1956). This means that the students are only being challenged with a new situation that requires minimal identification for prompting or application of the rules, principles or concepts contained within the book. Given these preliminary results it is imperative that faculty go beyond simply assigning problems from the back of the book in order to help the student achieve learning at higher levels of Bloom's Taxonomy.

The construction and creation of alternative problems and strategies is time consuming and requires a significant commitment on the part of the instructor. However, the rewards for well conceived problems for the committed teacher far outweigh the time requirement.

As noted earlier $89.4 \%$ of end of chapter problems were written at Level 2 or less on the Bloom's scale. Not only are the problems low on the Bloom's Taxonomy (Bloom \& Krathwohl, 1956) scale, but also the students are often cued directly as to how to solve these problems. The most obvious cuing for the students is the fact that end of chapter problems tend to directly reflect only the material contained within that chapter. Also, many problems are simply a restatement of an earlier example problem contained and worked within the chapter. Other forms of cuing for the students include statements next to the problem or in the margin, which specifically tell the student exactly what kind of problem they are being asked to work. An example would be a finance textbook that included "Net Present Value" next to the problem, cuing the students to do a net present value computation. The students did not have to figure out the most important part of the problem. They have formulas, tables or financial calculators to aid in producing an answer, the real challenge to the type of end of chapter problems found in the finance text was knowing what had to be computed. But, there was no challenge for these students because they were told what computation to do.

Some textbooks that were reviewed had cases at the end of a chapter. However, the vast majority of these cases were narrowly defined, long word problems that failed to capture the complexities of a well developed case. These case problems, by and large, were at Level 3 on the taxonomy. Of the 942 end of chapter problems, including cases, internet exercises and other matters for discussion, the authors found only 2 problems which met our definition of judgment on the taxonomy scale.

Within each discipline considered the results were fairly consistent. The results are summarized in Figure 1.

Figure 1

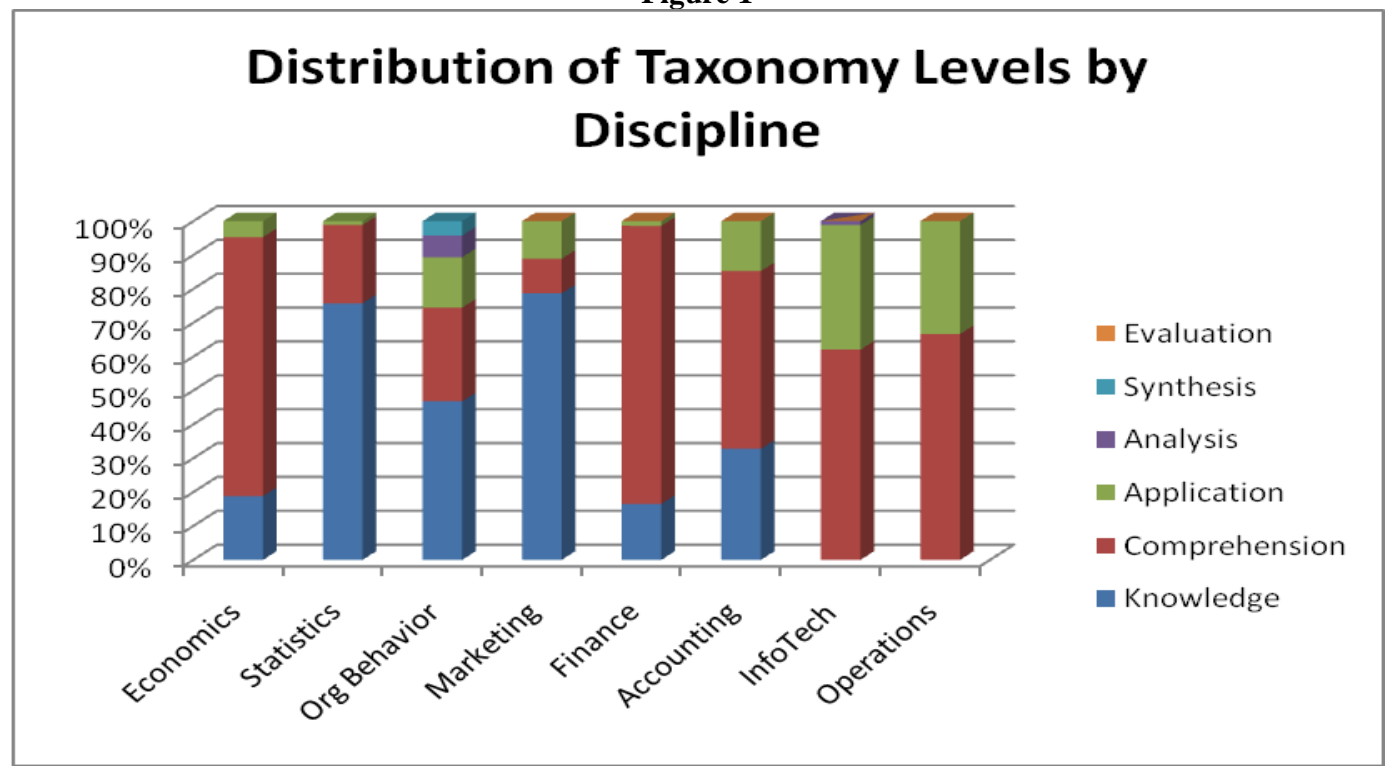




\section{IMPLICATIONS OF FINDINGS}

Based on our assessment of the selected text's end of chapter problems - students are not being required to move past the Application level on the Bloom's Taxonomy (Bloom \& Krathwohl, 1956) scale. The correct answers are almost always attainable from the material contained within that chapter. Mastery of narrowly defined problems often cued at the end of chapters creates a false sense of understanding for the student of the subject matter. Based on our review, the end of chapter problems rarely challenge the students to think beyond the subject and most commonly never beyond the chapter. The implication of these narrowly defined problems contained within very specific and narrowly defined disciplines is that students do not understand the world of business and do not comprehend subjects in a broader context. This one to one relationship between end of chapter problems and the material within the chapter creates a narrow superficial and false understanding of business. It is necessary to supplement end of chapter problems with alternative learning strategies. Textbooks do a very good job at conveying information and comprehension to students. However, our findings suggest limitations of textbook usage in taking students to the Application level or beyond.

\section{STUDY LIMITATIONS}

This preliminary study is not without limitations. We have, based on input from colleagues in the respective disciplines, selected one text book from the eight studied disciplines. Ideally we would have included multiple text books from each discipline. However, we have emphasized that this is a first step in what should be a long process. Future research should expand the number and types of text book offerings in each discipline in order to gain a more expansive view on end of chapter question content. Our study reveals diffiencies in the text books that we selected for inclusion in our project. While we cannot say that all text books have these same problems, we do believe that our research has revealed a reoccurring issue with end of chapter problem content.

\section{RECOMMENDATIONS}

The key for faculty to take their students outside of this limited context and to move them to higher levels on Bloom's Taxonomy (Bloom \& Krathwohl, 1956) is to challenge the students beyond those end of chapter problems currently provided by text books. Problems similar to those found at the end of chapters can be written that require student to integrate some topic from a previous chapter. The integration without an obvious prompt will move the student to Level 3 (Application) or Level 4 (Analysis). For example, when teaching about unemployment in an Economics class, the instructor may provide the students a question that involves an unexpected change in the exchange rate. This creates a new situation and forces the students to relate this affect to their newly acquired knowledge about unemployment. Likewise, in a Statistics course when covering the distribution of sample means the instructor could ask the students what is the probability that two samples taken independently will both be above some specified value. This forces the students to make a new application of the probability of independent events, a topic that was likely covered three or four chapters earlier.

Alternative learning strategies need to be implemented that will integrate disciplines into new situations without an obvious prompt. The biggest hindrance to reaching the Analysis (Level 4) or Synthesis (Level 5) with end of chapter problems appeared to be the close relationship between the end of chapter problem and the chapter itself. Implicit or explicit prompting of the students about what is needed to answer the question is the biggest hindrance to the problems that we reviewed reaching Level 3. Analysis (Level 4) can sometimes be addressed within the context of the textbook. However, challenging the students to make a generalization in another discipline is an excellent way to get students to function at Level 4 . Level 4 requires the students to integrate multiple topics from several different chapters within a textbook and to generalize this into a new situation. Level 5 (Synthesis) requires the strategy that accesses the appropriateness of a decision. Judgment requires a broad assessment of a decision and can only be achieved by viewing the ramifications of a decision across multiple disciplines. Implications across multiple disciplines simply have not been found in any of the textbooks we reviewed

One solution for reaching Level 4 and beyond may be Problem Based Learning (PBL). Problem based learning is a tool that has the potential to connect the courses within a business curriculum and to help achieve the 
desired assessment outcomes. Problem based learning is a process where the learner actively constructs knowledge and makes cognitive connections between theories and knowledge in a broad spectrum. Problems serve as a stimulus for learning. The students encounter problem-solving situations in small groups. Facilitators are there to enhance but not control the learning process.

PBL problems form the organizing focus and stimulus for reaching levels 4 and 5. They are vehicles for the development of critical problem solving skills. They require the students to gather and assimilate new information through self-directed learning. When student groups are confronted with a problem, the students must organize prior knowledge and attempt to identify the nature of the problem. This forces students to pose questions about what they do not understand and to try to relate what they have acquired and do understand to the problem. Students must design a plan to solve the problem and identify the resources needed. The outcome of employing a well designed PBL problem is that the students will improve their problem solving skills, become self directed in their learning process, will enhance their critical thinking, broaden their base knowledge, and make connections between various disciplines. Working in teams will also enhance their ability to communicate and work together in a situation similar to the environment they will encounter in the business world and will improve their ability to communicate both written and orally on a subject which required them to integrate knowledge from many different areas.

Additionally, active learning strategies can prove valuable and stimulating for students to think at a higher level. Developing cross-disciplinary PBL problems are an excellent way to bring students to a higher level. Cohort scheduling could be used to aid and facilitate in using cross-disciplinary problems. For example, the same students could be taking both an accounting class and a finance class and a cross disciplinary problem that ties finance to accounting could be developed for use in both classes. Forcing students to understand the implications of accounting for finance and finance for accounting would facilitate taking the students from level 2 or 3, to level 4 or 5. Cases contained at the end of chapter problems were too narrowly focused to achieve the desired results of a case. It is our opinion that selecting cases from other sources, such as case journals, would lead to better integration of multiple topics for the students. Cases can be an excellent vehicle to take students to level 4 and sometime to level 5. The major disadvantage of cases is that the students do not have to determine what information is needed to address the issue. The self-contained nature of cases makes it more difficult for them to challenge the student at level 5.

Synthesis and Evaluation requires a student to go beyond judgment. The students must be challenged to function across a curriculum to reach these levels. While this paper does not offer specific means of achieving Level 6 (Evaluation) learning we do provide means for moving beyond the initial levels of the Taxonomy (Knowledge and Comprehension) and into more challenging domains of learning such as Application, Analysis, and Synthesis. Without this progress, and the necessary shift in thinking regarding the utility of end of chapter problems, Level 6 learning will continue to evade our grasp.

\section{AUTHOR INFORMATION}

For the last 23 years Dr. Jennings Marshall has taught at Samford University's Brock School of Business in Birmingham, Alabama. Prior to that he taught for nine years at Tennessee Technology University. He has been involved in outcomes based learning with a FIPSE grant, and later was involved with problem based learning through a PEW grant. Marshall received a Bachelor's degree in Math and Economics from Kentucky Southern College and an MA and Ph.D. in Economics from the University of Kentucky.

Dr. Charles M. Carson is an Assistant Professor of Management at Samford University's Brock School of Business. Carson received his Ph.D. from the University of Mississippi. His research interests include family business issues, case writing, and workplace attendance interventions. His research has been published in leading academic journals including Educational and Psychological Measurement, Human Performance, and Management Decision. 


\section{REFERENCES}

1. AACSB International Eligibility Procedures and Accreditation Standards for Business Accreditation. Revised January 31, 2008. www.aacsb.edu.

2. Anderson, David R., Sweeney, Dennis J., and Williams, Thomas A., (2005) Statistics For Business and Economics, ${ }^{\text {th }}$ Edition. Cincinnati, Ohio, South-Western, Thomson Learning.

3. Bloom, B. S. \& D. R. Krathwohl. (1956). Taxonomy of educational objectives: The classification of educational goals, by a committee of college and university examiners. Handbook 1: Cognitive domain. New York, Longmans.

4. Boone, Louis E., and Kurtz, David L., (2006). Contemporary Marketing, $12^{\text {th }}$ Edition. Fort Worth, Texas, Harcourt College Publishers.

5. Deppe, Larry A., Sonderegger, Emory O., Stice, James O., Clark, D. Cecil, and Streuling, G. Fred. (1991). (Fall). Emerging Competencies for the Practice of Accountancy. Journal of Accounting Education, 9(2), 257-290.

6. El-Khawas, E. (1990). Campus trends 1990. Higher Education Panel Report No 80. Washington, D.C.: American Council on Education.

7. Kimmel, Paul D., Weygandt, Jerry J., and Kieso, Donald E., (2003). $3^{\text {rd }}$ Edition. Financial Accounting: tools for business decision making. New York, New York. John Wiley \& Sons, Inc.

8. Laudon, Kenneth C. and Laudon, Jane P. (2004) Management Information Systems, $8^{\text {th }}$ Edition. Upper Saddle River, New Jersey, Prentice Hall.

9. McConnell-Brue, (2005) Economics - Principles, Problems and Policies, 16th Edition. New York, New York. McGraw-Hill Companies.

10. Robbins, Stephen P., (2005) Organizational behavior, $11^{\text {th }}$ Edition. Upper Saddle River, New Jersey, Prentice Hall.

11. Ross, Stephen A., Westerfield, Randolph W., and Jordan, Bradforf D., (2004) Essentials of Corporate Finance, $4^{\text {rd }}$ Edition. Boston, Massachusetts, McGraw-Hill.

12. Schonberger, Richard J. and Knod, Edward M., (2001) Operations Management, $5^{\text {th }}$ Edition. New York, New York. McGraw-Hill Companies. 
NOTES 